\title{
PerCursos
}

\section{Meu filho é autista, e agora? Estratégias de enfrentamento familiar perante o diagnóstico do autismo}

\begin{abstract}
Resumo
O presente artigo tem como tema central a experiência de famílias com filhos diagnosticados com o Transtorno do Espectro Autista (TEA) e as suas estratégias de enfrentamento diante do diagnóstico. O objetivo geral do estudo foi descrever e analisar, através de entrevistas com três mães, a experiência familiar (impressões, reações e emoções) a partir do momento em que os seus filhos receberam o diagnóstico do TEA. Essas três mães se propuseram a representar suas famílias na pesquisa. Dessa forma, foi realizada a análise do conteúdo das entrevistas, através de uma sistematização temática, para a leitura analítica do tema proposto, tendo como base a literatura científica disponível. Os principais resultados apontam para a busca do conhecimento, por parte da família, como principal estratégia de enfrentamento para lidar com as demandas estressoras diante da experiência mencionada. Assim, foi observado que as famílias buscam estratégias práticas e objetivas, mas também procuram apoio social e religioso. Vale ressaltar que a condição socioeconômica e cultural das famílias pode refletir diretamente na forma como enfrentam o diagnóstico, em função da acessibilidade à orientação especializada e a recursos profissionais. Portanto, compreendese que a presente pesquisa alcançou o seu objetivo ao descrever a experiência familiar após o diagnóstico do TEA, mas não reflete todas as realidades familiares.
\end{abstract}

Palavras-chave: Transtorno do Espectro Autista. Família. Estratégias de enfrentamento.

\author{
Ana Suelem Lima Freitas \\ Graduada em Psicologia pelo Centro \\ Universitário Maurício de Nassau. Pós- \\ graduanda em Análise do Comportamento \\ Aplicada ao Autismo pelo Instituto de \\ Educação e Pesquisa em Saúde e Inclusão \\ Social - IEPSIS. Psicóloga Clínica no Espaço \\ Permita-se. \\ Brasil \\ analima.77@hotmail.com
}

\section{Karina Santos de Jesus}

Graduada em Psicologia pelo Centro

Universitário Maurício de Nassau. Pós-

graduanda em Análise do Comportamento

Aplicada ao Autismo pelo Instituto de

Educação e Pesquisa em Saúde e Inclusão

Social - IEPSIS. Supervisora no Instituto

Habilidades Para Vida.

Brasil

psikarinasantos@gmail.com

\section{Verônica Gomes Nascimento}

Doutora em Psicologia pela Univ. Federal da Bahia - UFBA e em Ciências da Educação pela Université Paris 8 Vincennes-Saint-

Denis. Professora do Centro Universitário

Maurício de Nassau - UNINASSAU.

Brasil

veronica_gomes_nascimento@hotmail.com

\footnotetext{
Para citar este artigo:

FREITAS, Ana Suelem Lima; JESUS, Karina Santos de; NASCIMENTO, Verônica Gomes. Meu filho é autista, e agora? Estratégias de enfrentamento familiar perante o diagnóstico do autismo. PerCursos, Florianópolis, v. 21, n.47, p. 171 - 196, set./dez. 2020.
} 


\title{
My child is autistic, what now? family coping strategies before the diagnosis of autism
}

\begin{abstract}
This article has as its central theme the experience of families with children diagnosed with Autistic Spectrum Disorder (ASD) and their coping strategies in the face of the diagnosis. The study's general objective was to describe and analyze, through interviews with three mothers, the family experience (impressions, reactions, and emotions) from the moment their children were diagnosed with ASD. These three mothers proposed to represent their families in the research. Thus, the analysis of the content of the interviews was carried out, through a thematic systematization, for the analytical reading of the proposed theme, based on the available scientific literature. The main results point to the family's search for knowledge as the main coping strategy to deal with stressful demands in the face of the mentioned experience. Thus, it was observed that families seek practical and objective strategies, but also seek social and religious support. It is worth mentioning that the socioeconomic and cultural conditions of families can directly reflect on the way they face the diagnosis, due to the accessibility to specialized guidance and professional resources. Therefore, it is understood that the present research achieved its objective by describing the family experience after the ASD diagnosis, but it does not reflect all family realities.
\end{abstract}

Keywords: Autism Spectrum Disorder. Family. Coping strategies. 


\section{Introdução}

A chegada de uma criança é um momento de grandes mudanças para uma família, promovendo desde responsabilidades adicionais, reestruturação do contexto familiar, até o remanejamento de prioridades (VILLARES; LAGE, 2017). Segundo Begossi (2003), a estrutura familiar pode atenuar ou acentuar todo o processo da gravidez, o qual engloba mudanças físicas, além de mudanças nos papéis sociais e na identidade dos sujeitos, a depender da estruturação familiar. Ou seja, as mudanças causadas pela gravidez na vida de uma família podem causar estresse na relação familiar e na relação da mãe com a gestação em si.

Atrelados a essas mudanças existem o investimento e a idealização de todo o futuro do recém-chegado. Segundo Ramos (2015), os pais tendem a planejar toda a vida da criança. Mannoni (1985) sugere que o nascimento do filho acompanha a possibilidade de preenchimento das lacunas na vida dos pais. A autora aponta a sobreposição que as fantasias e os desejos renunciados na infância do adulto têm sobre a imagem da criança "real". No entanto, tal processo se mostra comprometido quando os pais se deparam com realidades que fragilizam suas expectativas de um filho "ideal”, como é o caso do diagnóstico do Transtorno do Espectro Autista (TEA).

O TEA decorre de perturbações de desenvolvimento neurológico e, como se trata de um espectro, suas características são diferentes de caso para caso e existem três classificações de acordo com o grau de comprometimento da linguagem, interação social e cognição, sendo que algumas destas características estão presentes em todas as classificações. Para a família, em razão do TEA não possuir uma cura, pois se trata de uma característica do sujeito, os sentimentos negativos possuem um impacto maior no contexto familiar do que em casos de outros diagnósticos que possuem a cura como potencial, o que acaba gerando mais estresse. Além disso, como ainda não se sabe a causa, as famílias tendem a esperar uma cura ou uma reviravolta no caso (MAIA et al., 2016).

Favero-Nunes e Santos (2010) sugerem que os sentimentos de dúvidas com o futuro do filho e o inconformismo com a situação perduram muito após a chegada do diagnóstico. Para Alves (2012, p. 90), “é preciso vivenciar o processo de luto pelo filho 
que foi idealizado, para que seja possível estabelecer um vínculo de amor e cuidado com o filho que nasceu". Os autores relatam que é fundamental que ocorra uma elaboração desse luto e, dessa forma, o diagnóstico pode ter a função de materializar e tornar palpável o problema a ser enfrentado. Conforme Monteiro e colaboradores (2017), o diagnóstico é uma ferramenta que facilita o acesso a informações sobre o desenvolvimento do indivíduo dentro do espectro, como também sobre as intervenções mais adequadas para cada caso. Entretanto, segundo Silva e Mulick (2009), o diagnóstico pode, também, rotular e limitar o indivíduo e prejudicar o seu desenvolvimento. Os pais podem atrelar tudo ao diagnóstico e mudar o olhar para a criança que ali existe além da condição diagnóstica (RAMOS, 2015). Favero-Nunes e Santos (2010) ainda apontam que, após o impacto inicial, a família tende a "acostumar-se" com os comportamentos da criança, aceitando-a e procurando as melhores condições de vida possíveis para o filho.

Gonçalves e Bittar (2016, p.40) complementam essa ideia afirmando que "apesar de doloroso, porque inclui a percepção da perda, o luto é um processo que visa representar e acomodar esta perda, portanto, um processo necessário". No caso do diagnóstico do TEA, mesmo que não seja de fato uma morte do filho, há uma morte simbólica do indivíduo que foi idealizado. O luto é importante não apenas para os pais, mas para todo o contexto familiar e social da criança.

Além disso, Williams e Wright (2008) diferenciam a forma como cada família lida com o seu luto após o diagnóstico, ou seja, as famílias utilizam diversas estratégias de enfrentamento para lidar com a perda do filho idealizado.

A partir das ideias apresentadas, explicita-se que o interesse do estudo realizado foi pesquisar sobre como a família reage depois que recebe o diagnóstico de TEA e quais são as estratégias de enfrentamento (impressões, reações e emoções) encontradas pela mesma. A pesquisa foi fundamentada na literatura de referência sobre a temática em questão, tendo como os objetivos específicos:

- Observar as características da configuração familiar de cada família entrevistada;

- Verificar quais são os significados atribuídos a um filho, pela família;

- Investigar como a família enfrenta a perda do "filho idealizado", a partir do 
diagnóstico de TEA;

- Identificar e analisar quais são as estratégias de enfrentamento encontradas pela família no desenvolvimento dos seus filhos e as suas repercussões.

Dessa forma, esta pesquisa propôs dialogar com a literatura já existente acerca das estratégias de enfrentamento familiar frente ao diagnóstico do TEA, no intuito de contribuir para a continuidade da discussão da temática no âmbito social e acadêmico no contexto brasileiro. Além disso, intenciona-se servir como base para expandir o conhecimento sobre o TEA em relação às estratégias familiares de enfrentamento às repercussões do diagnóstico. Compreende-se que o estudo pode ser visto como uma contribuição para os pais, mas também para os profissionais que lidam diretamente ou indiretamente com o tema do autismo, visto que conhecer os processos que ocorrem após o diagnóstico do TEA dentro da família pode auxiliar na formação de um trabalho consistente e efetivo.

\section{Autismo}

O Transtorno do Espectro Autista (TEA), em sua definição, não se caracteriza como uma doença, mas sim como um distúrbio no desenvolvimento. Dessa forma, tratase de uma síndrome comportamental, podendo ter vários graus de severidade: leve (nível 1), moderado (nível 2) e severo (nível 3). Tais graus correspondem aos impactos nas áreas da linguagem, cognição e interação social (AMERICAN PSYCHIATRIC ASSOCIATION, 2014; GADIA; TUCHMAN; ROTTA, 2004; PINTO et al., 2016). Quanto à etiologia, não é possível afirmar uma única causa para o desenvolvimento do TEA; sendo assim, a literatura descreve essa etiologia como multicausal (PINTO et al., 2016). Segundo Silva e Mulick (2009), existe um consenso entre os especialistas de que se trata de disfunções do Sistema Nervoso Central (SNC). Entretanto, esse pensamento nem sempre foi (e não é ainda) unanimidade entre os pesquisadores e especialistas.

O termo "autismo" foi utilizado pela primeira vez em 1911, por Bleuler, para designar alguns distúrbios comportamentais. Em 1943, Kanner descreveu comportamentos de algumas crianças cujas características repousavam sobre a mesma 
definição utilizada anteriormente por Bleuler (GADIA; TUCHMAN; ROTTA, 2004). Nas décadas de 1950 e 1960, o autismo teve a sua etiologia relacionada a uma condição provocada por uma consequência afetiva ocasionada pelos pais, sobretudo pela mãe, a qual foi considerada como uma "mãe geladeira" (KLIN, 2006). Já em 1976, Ritvo relacionou o autismo a um déficit cognitivo, como um distúrbio comportamental (GADIA; TUCHMAN; ROTTA, 2004;). E, em 1978, Michael Rutter propôs uma nova definição para o transtorno, o que possibilitou ao autismo ser reconhecido como "uma nova classe de transtornos" (KLIN, 2006, p.2).

Para o diagnóstico do TEA, são utilizados os critérios do Manual Diagnóstico e Estatístico de Transtornos Mentais em sua $5^{\text {a }}$ ed. (AMERICAN PSYCHIATRIC ASSOCIATION, 2014). São adotados os seguintes critérios no DSM-V: dificuldades com comunicação e interação social em vários contextos; padrões restritos e repetitivos de comportamento, interesses ou atividades; sintomas identificados precocemente (antes dos 36 meses de idade); sintomas causadores de prejuízos significativos para o indivíduo em diversos contextos; e comunicação social abaixo do padrão pré-estabelecido para a fase de desenvolvimento (AMERICAN PSYCHIATRIC ASSOCIATION, 2014).

Quanto à classificação dos níveis, ou seja, gravidade ou severidade, o DSM-V apresenta algumas premissas no que diz respeito ao apoio necessário para o cumprimento das atividades diárias, cuja intensidade é relativa ao grau de comprometimento das habilidades do sujeito, ou seja, o suporte deve ser menor no grau leve e maior no grau severo (AMERICAN PSYCHIATRIC ASSOCIATION, 2014). Além desses critérios abordados pelo DSM-V, uma avaliação psicológica é extremamente importante, pois:

fornecerá informações detalhadas acerca do funcionamento cognitivo e adaptativo da criança, o que é essencial para a formulação de um plano de intervenção individualizado. (SILVA; MULICK, 2009, p.126)

Sobre a intervenção, Bosa (2006) aborda alguns objetivos dessa ação, sendo eles o estímulo ao desenvolvimento da comunicação e interação social, o aprimoramento do aprendizado e a capacidade de resolver problemas e a diminuição dos comportamentos 
estereotipados. Lampreia (2007) aponta, também, a importância da intervenção ser feita precocemente. A autora afirma que a intervenção precoce compreende "as peculiaridades e desvios do desenvolvimento da criança portadora de autismo, a partir, ou à luz, do desenvolvimento típico" (LAMPREIA, 2007, p. 106). Costa (2014) analisa a importância da intervenção precoce a partir do pensamento de Siegel, considerando a mesma como um processo que atenua as consequências negativas do TEA, assim como potencializa as consequências da intervenção para o desenvolvimento da criança diagnosticada. Entretanto, existem autores que entendem que quando o diagnóstico surge mais como um fator para a medicalização e patologização do que com o objetivo de promover intervenções saudáveis, há uma redução na capacidade da criança em desenvolver-se, limitando o indivíduo a apenas um aspecto de sua vida, não permitindo que seja visto todo o potencial deste (MOYSÉS; COLLARES, 1997).

Conforme Viégas (2015), a rotulação responsabiliza o indivíduo pela dificuldade, limitando-o somente à sua excepcionalidade, retirando do meio a responsabilidade de garantir os caminhos para que a criança se desenvolva. Cria-se, então, a ideia de que não há o que fazer para que o sujeito diagnosticado eleve suas capacidades, visto que os seus problemas o impedem de aprender.

A partir disso, considerando as abordagens psicológicas, compreende-se que a visão psicanalítica tem lançado um olhar específico em relação ao autismo, enfatizando a importância de olhar o sujeito além do diagnóstico. Nesse sentido, a partir da perspectiva psicanalítica, nota-se a relevância da questão do luto do filho “ideal”, ou seja, da morte simbólica do filho que foi idealizado.

A relação entre a psicanálise e o TEA começa em 1930, a partir da publicação do “caso Dick”, por Melanie Klein. Ao fazer uma observação comportamental do paciente, Klein observou alguns tipos de comportamentos que não se encaixavam nos critérios diagnósticos dos distúrbios reconhecidos na época. Dessa forma, por não ter entidade nosológica ainda conhecida, o garoto foi diagnosticado com "demência precoce" (GONÇALVES et al., 2017).

Para Marfinatti e Abrão (2014), a psicanálise enxerga a etiologia do autismo a partir de um estabelecimento não saudável do ego, o que faz com que o indivíduo 
acometido tenha um retraimento frente às suas experiências e, por consequência, apresente dificuldades para lidar com suas vivências. Já Macedo (2010) apresenta a etiologia do autismo baseado em duas perspectivas, sendo elas a orgânica e a psicogênica. Na orgânica, o TEA tem sua causa em fatores orgânicos, enquanto a psicogênese explica sua causa a partir de uma falha na relação entre a mãe e o bebê.

Quanto ao diagnóstico, faz-se necessária a observação dos sintomas, suas restrições e como isso influencia nas suas relações sociais (ROCHA, 2009). Batista (2013) preconiza o diagnóstico do TEA pela psicanálise porque esta permite enfatizar a subjetividade e não apenas a observação das estereotipias, apoiando-se na noção psíquica de sujeito, aumentando assim as possibilidades de valorização da singularidade do indivíduo. Para a intervenção, Gonçalves e colaboradores (2017) apontam as seguintes metodologias de tratamento: a) o manejo da transferência referente ao vínculo existente entre paciente e analista e a habilidade do profissional para utilizá-lo durante o tratamento; b) a reestruturação psíquica através do desenvolvimento da capacidade simbólica, para que a criança consiga, dentro do seu desenvolvimento, se organizar e reconhecer as representações simbólicas, o que permite uma reorganização psíquica; c) o tratamento com ênfase no jogo simbólico, tendo em vista fortalecer o vínculo entre paciente e analista; e d) a aquisição da linguagem, tendo como objetivo promover melhoras nos sintomas do TEA.

\section{Luto pela perda do filho idealizado}

As ideias sobre a criança surgem na família muito antes de seu nascimento, algumas famílias planejam até mesmo a profissão e com quem a pessoa manterá vínculos afetivos. Para Levin (2005) e Costa (2014), esse processo implica na novidade, momento em que se criam várias hipóteses baseadas no próprio significado do ser filho/a. Os pais projetam os planos de vida nos filhos e ressignificam o próprio espelho, sendo que o mesmo também pode ocorrer com os futuros avós. Isso ocorre pelo ideal que se reflete em ser pai/mãe e cada ideal é representado a partir de suas próprias vivências como filho/a (LEVIN,2005).

Quando constatam que a criança real pode ser, ou é, diferente da criança 
desejada e idealizada, essas significações narcisistas são frustradas e há um momento de ressignificação, no qual os pais enfrentam seus próprios ideais, vivenciando conflitos a partir dos seus narcisismos e gerando oposições entre a criança desejada e a criança real (LEVIN, 2005). Assim, “há a morte do filho idealizado, e tal constatação gera profunda tristeza, medo do futuro, frustração e vergonha" (ALVES, 2012, p. 90). O filho se encontra ali, mas não do jeito que a família idealizou.

Conforme Ramos (2015), ao receber o diagnóstico de TEA, observam-se três caminhos comuns seguidos pelas famílias. No primeiro, há a superproteção e o amor incondicional, em que o filho é impedido de viver de forma independente e dentro de suas capacidades. Já no segundo caminho, ocorre um impedimento das capacidades do indivíduo; os pais tendem a excluir e se desvincular do filho, transformando o amor familiar em ódio. Nestes dois caminhos ocorre a criação do estereótipo da imagem do sujeito, o filho passa a ser definido pelo diagnóstico. No terceiro caminho, "os pais passarão pela elaboração da 'morte' do filho ideal e farão a ressignificação desse ideal que foi perdido com o nascimento do 'filho deficiente"' (RAMOS, 2015, p. 23-24). Villares e Lage (2017) apontam que, muitas vezes, ao se darem conta de que o filho real não condiz com o filho idealizado, as mães passam por um processo de luto semelhante ao descrito por Kübler-Ross (1969), a qual fez uma pesquisa com pacientes em fase terminal dividindo o processo de luto em cinco estágios, sendo eles: negação, raiva, barganha, depressão e aceitação. O luto pode ocorrer de forma diferente para cada paciente e para cada família que possui um membro em situação de doença grave ou morte. A família pode passar por todas as fases propostas por Kübler-Ross, na ordem apresentada pela autora, fora dessa ordem ou mesmo pulando etapas (Kübler-Ross, 1969).

No entanto, vale mencionar que, com a criança presente, o luto se manifesta de forma diferente do habitual. Segundo Kübler-Ross (1969), no primeiro estágio, o sujeito e/ou família criam um mecanismo de defesa e negam o diagnóstico, principalmente quando é dito de forma abrupta, sendo que esse estágio pode passar rápido ou permanecer por um período mais prolongado. Diante disso, foi feita, no presente estudo, uma associação da teoria de Kübler-Ross (1969) com as considerações teóricas de Ramos (2015), o qual aborda a morte do filho "ideal” como uma morte simbólica. Nota-se, nesse sentido, que é comum os pais passarem a duvidar do diagnóstico e buscarem opiniões de 
outros especialistas (RAMOS, 2015), o que mostra semelhanças com a vivência desse primeiro estágio do processo do luto.

No segundo estágio, que ocorre quando o paciente e/ou a família não sentem mais a negação, surge a raiva. Nele, o paciente e/ou a família tendem a se deparar com sentimentos de mágoa, revolta e inveja (KÜBLER-ROSS, 1969). Portanto, compreende-se assim que saber sobre o diagnóstico, no caso do autismo, pode fazer com que os pais se sintam culpados pela condição do filho e se questionem sobre o porquê de aquilo acontecer com eles (RAMOS, 2015).

O terceiro estágio é a barganha, que pode ser relacionada à busca das famílias pela fé ou por sua crença (KÜBLER-ROSS, 1969). O quarto estágio é a depressão, o qual ocorre quando não se sente mais a negação, quando se percebe que a raiva não resolverá o problema e que não existe mais a possibilidade de barganhar (KÜBLER-ROSS, 1969).

Considerando a associação teórica mencionada, compreende-se que quando o filho idealizado "morre", a família se prepara para a fase da aceitação, tendo em vista a melhor qualidade de vida para seu filho e sua família (FAVERO-NUNES; SANTOS, 2010). Segundo Kübler-Ross (1969), o quinto e último estágio caracteriza-se como esse processo de aceitação, o qual se difere do estado de depressão apenas porque o que antes funcionava como uma fuga, aqui aparece como a valorização daquilo que realmente importa, diminuindo a necessidade da relação com o que é alheio à situação. Associando com a questão do diagnóstico de deficiência e/ou autismo, nota-se que a "morte" do filho idealizado é percebida como uma realidade inevitável e este é o momento de procurar informações e ajuda especializada (RAMOS, 2015).

\section{Estratégias de enfrentamento a partir do diagnóstico}

Segundo Santos (2016), é de grande importância direcionar um olhar aos familiares e não somente ao membro diagnosticado, pois a excepcionalidade não só afeta o indivíduo em si, mas todo o contexto familiar, podendo acarretar mudanças de cunho social, emocional, funcional e psicológico, gerando desafios em todo o núcleo familiar.

Para lidar com esta situação, nota-se que algumas famílias buscam os melhores 
profissionais do mercado, recorrem às pesquisas e se especializam; outras se apegam à religião e a grupos de apoio presenciais ou pelas redes sociais. Outras famílias escondem o diagnóstico dos outros membros da família e não buscam intervenção. E ainda existem famílias que não se importam com o diagnóstico e continuam suas vidas como se o filho não precisasse de uma intervenção para ajudar no seu desenvolvimento (LEVIN,2005). Tais estratégias são apresentadas por Lazarus e Folkman (1984) e Atkinsons e colaboradores (1995), citados por Schmidt, Dell'Aglio e Bosa (2007), como coping, ou seja, todo "o conjunto de esforços, tanto cognitivos quanto comportamentais, que os indivíduos mobilizam diante de uma situação de estresse pode ser entendido como enfrentamento" (SANTOS, 2016, p.3234).

Nesse sentido, compreende-se, em relação à experiência familiar diante do diagnóstico do TEA, que há uma tentativa de amenizar a maneira como os eventos estressores atuam sobre o indivíduo e família, o que permite a inserção de novas posturas frente à nova informação recebida. Na seção anterior, através de Ramos (2015), foram explicitados os caminhos possíveis seguidos pelas famílias ao receberem o diagnóstico de alguma deficiência. Vale mencionar, neste momento, a análise postulada por Levin (2005) sobre a mesma questão dos três caminhos. O primeiro e o segundo caminhos apontam para o amor incondicional e a negação total da identidade do filho, respectivamente, o que impede a formação da identidade do filho. No terceiro percurso, considerado pelo autor como a trajetória mais saudável, é necessário que ocorra o processo de luto, em que acontece a ressignificação do que seria o filho "perfeito", trazendo novas idealizações de um modo geral (LEVIN, 2005). Levin aponta a intervenção para a quebra da concepção de fusão entre o que é "filho" e o que é "deficiência”, para que se dê lugar à separação de ambos, favorecendo a elaboração individual desses conceitos. Por isso, o autor enfatiza a importância de ajudar os pais a realizarem e aprofundarem a relação - o laço cênico de amor - com o filho e não com a deficiência, ou seja, faz-se necessário apoiar a família para que elabore a deficiência de forma que sua existência não seja negada, mas que também não apague a função de filho presente na criança.

Schmidt, Dell'Aglio e Bosa (2007) sugerem que existem nove categorias de estratégias de enfrentamento na experiência da família com algum membro com TEA : 1) ação agressiva (física, verbal ou psicológica); 2) evitação (tentativas de afastamento da 
situação de estresse, fuga ou distanciamento); 3) distração (comportamentos que adiam a interação com o estressor, através de outras atividades); 4) busca de apoio social/religioso; 5) ação direta (diretamente sobre o estressor, modificando suas características); 6) inação (incapacidade de agir sobre o estressor, bloqueio de atitudes); 7) aceitação; 8) expressão emocional; 9) reavaliação/planejamento cognitivo (são as tentativas de ressignificar a situação estressora).

\section{Método}

Este estudo se trata de uma pesquisa descritiva, pois objetiva alcançar uma descrição das características de determinado fenômeno (GIL, 2008). Esta pesquisa não elabora hipóteses a priori, pois seu objetivo principal é o conhecimento acerca dos aspectos relativos ao objeto investigado. Nesse sentido, caracteriza-se a pesquisa como qualitativa, porque o interesse envolveu um aprofundamento de dados, sendo realizada através de entrevistas por pautas que, segundo Gil (2008), estabelecem uma quantidade de perguntas diretas dentro de pautas que se relacionam entre si, mas garantem a flexibilidade necessária para que a fala do entrevistado seja livre. Além disso, espera-se que a partir de seus resultados, desenvolvam-se mais discussões sobre o tema (CRESWELL, 2007).

A pesquisa contou com a participação de três mães de crianças que receberam o diagnóstico do Transtorno do Espectro Autista (TEA). Como critério de inclusão dos participantes, foi estabelecido que as famílias deveriam possuir membro(s) - filho(a) com o diagnóstico conclusivo do TEA. Ou seja, as famílias que possuíam membro(s) filho (a) - que estão em processo de avaliação diagnóstica no momento da realização do estudo não puderam participar da pesquisa. O contato com as famílias se deu a partir de uma relação profissional que existia entre uma das autoras e uma das mães, a qual indicou mais duas pessoas para a pesquisa. Vale ressaltar que não havia vínculos familiares profissionais diretos entre as partes. O local das entrevistas foi escolhido pelas participantes de acordo com o que fosse mais confortável para as mesmas.

Foi utilizada uma entrevista semiestruturada, composta por 14 questões diretas. As perguntas foram divididas em 3 partes: A) dados pessoais; B) aspectos sociais - em 
qual contexto essa família está envolvida (religião, cultura, classe social, escolaridade); e C) perguntas principais. Os temas envolveram, sobretudo, as questões referentes ao diagnóstico de TEA e as estratégias familiares encontradas para lidar com as informações presentes no laudo/relatório diagnóstico.

Os dados de pesquisa foram analisados a partir da análise do conteúdo, pois este procedimento permite "de forma prática, a inferência de conteúdos existentes na expressão da mensagem e que se replica no contexto social" (CAREGNATO; MUTTI, 2016, p. 682). Ou seja, os conteúdos expressos na fala podem ser categorizados e sistematizados de acordo com a representação que carregam. A partir da sistematização do material coletado, a análise do conteúdo permite a categorização dos temas da mensagem comunicada, o que caracteriza a análise temática (GERHARDT et al., 2009). Para Gerhardt e colaboradores (2009), a análise temática busca separar e sistematizar os conteúdos por temas, os quais podem ser definidos graficamente com palavras, frases ou resumos. Segundo Caregnato e Mutti (2016), é possível fazer esse agrupamento a partir da identificação do conteúdo comum entre eles à medida que estes surgirem na mensagem dos sujeitos de pesquisa.

Para a realização da análise temática, as entrevistas foram transcritas e, posteriormente, foram realizadas as três etapas propostas por Gomes (2002. p.75-76): pré-análise, caracterizada pela logística para a análise dos dados; a exploração do material, que se caracteriza pela análise do conteúdo obtido; e o tratamento dos resultados obtidos e interpretação, que representa o momento no qual é feito o embasamento do conteúdo obtido com a fundamentação teórica pré-existente. Nesse sentido, a análise temática foi organizada, no artigo, em quatro eixos, a saber: 1) O olhar além do estereótipo; 2) Mais além do que se pode imaginar; 3) Famílias X TEA; 4) Manobras.

O estudo seguiu os parâmetros éticos para realização de pesquisa com seres humanos, sendo aprovado pelo sistema CEP/CONEP através da Plataforma Brasil, obedecendo às diretrizes e normas das Resoluções n. 466/12 e 510/16 do Conselho Nacional de Saúde (CNS).

\section{Resultados e Discussões}


Como já mencionado, para a realização desta pesquisa, foram convidadas famílias de crianças com diagnóstico fechado de TEA. O estudo foi realizado com três mães: Laura, mãe de Lucas, Talita, mãe de Davi e Fernanda, mãe de João1. Cada mãe possui um filho dentro do TEA, os quais possuem idades entre 3 e 4 anos. Apesar da entrevista não ter sido limitada apenas às mães, foi observado que foram elas que se prontificaram a participar da pesquisa. As três possuem ensino superior completo, sendo duas na área de saúde e uma na área de educação. Em relação às condições socioeconômicas, as três mães estão situadas na classe média alta da cidade de Salvador (BA). Além disso, as três expressaram adotar o espiritismo como religião e relataram receber apoio significativo neste campo religioso. Tal aspecto pode caracterizar o que foi proposto por Schmidt, Dell'Aglio e Bosa (2007) em relação ao fato do apoio social/religioso, recebido pelas famílias, encontrar-se intimamente ligado à ação direta enquanto estratégia de enfrentamento.

As mães revelaram, também, um grande engajamento no estudo e no apoio às crianças situadas no Transtorno do Espectro Autista. Elas mencionaram que os filhos receberam o diagnóstico precocemente, o que ajudou no tratamento, o qual ocorre através do método da Análise Comportamental Aplicada (do inglês, Applied Behavior Analysis ou $A B A)$.

É relevante apontar que se trata de três famílias nucleares, pois são compostas por um casal com filhos, sem outros agregados (SOUSA; PERES, 2002). Conforme FáveroNunes e Santos (2005), grande parte das mães abandona a carreira para cuidar integralmente do filho autista. Nota-se, assim, a relevância de uma reformulação nos papéis de cada membro da família para lidar com as necessidades específicas da criança, assim evitando a sobrecarga de apenas um familiar. Ainda segundo os autores, as famílias que possuem um maior grau de instrução têm facilidade em conseguir apoio e melhores intervenções para os filhos. Tal aspecto se confirma neste estudo, considerando o fato de que o grau de instrução/escolaridade das famílias possibilitou mais acesso às informações, o que contribuiu para que os filhos tivessem grandes evoluções em função do apoio de especialistas e dos familiares, através da introdução de intervenções

\footnotetext{
${ }^{1}$ Os nomes das mães e dos filhos são fictícios como forma de garantir o anonimato dos participantes.
} 
precoces.

\section{Olhar além do estereótipo}

Embora atuem em áreas profissionais de saúde e educação, em que a probabilidade de estudo sobre o TEA seria mais evidente, as mães relataram que os seus conhecimentos sobre o autismo prévios à maternidade eram vagos. Dessa forma, o interesse em pesquisar sobre o transtorno foi despertado após o diagnóstico do filho. As mães relataram que se surpreenderam quando perceberam que não tinham estudado detalhadamente sobre o tema em seus cursos de graduação, como é possível perceber nos recortes das falas abaixo:

[...] eu não tive no meu currículo da graduação nenhuma disciplina que abordou o autismo [...]. (LAURA, 2019. Informação verbal)

[...] na minha faculdade [...] a gente aprende [...] como tratar crianças que tenham TEA, mas a gente tinha aquela imagem de criança que se balançava, a criança que não aceitava nenhum tipo de contato físico, uma criança que babava, aquele caso extremo que passava na televisão [...]. (TALITA, 2019. Informação verbal)

Paula, Belisasio e Teixeira (2016) corroboram a afirmação das mães, pois apontam que a formação dos profissionais ainda não garante um conhecimento pleno sobre o TEA, o que indica a necessidade dos cursos de graduação repensarem seus currículos. Apesar disso, as mães assumem contar com uma facilidade maior em encontrar informações sobre o TEA devido ao grau de instrução que possuem, conforme aponta Talita: “[...] eu tenho instrução e não sei, imagina o resto das famílias que não têm, que não tiveram essa oportunidade, o que elas vão achar? O que passa na televisão, o que passa na novela, aqueles casos de reportagem [...]." (TALITA, 2019. Informação verbal).

Diante disso, as mães consideram esse movimento de busca do conhecimento sobre a temática como algo fundamental para conhecer as especificidades do autismo e ampliar o olhar em relação aos sujeitos autistas, promovendo uma quebra dos estereótipos. 
As mães entrevistadas carregam, nas suas falas, expectativas de acordo com o que entendem sobre o que é um filho, como é possível verificar nos relatos abaixo:

[...] filho é tudo na minha vida, filho para mim é assim uma parte de mim, é ao mesmo tempo é o meu todo, é alguém muito especial, é por quem eu dedico a minha vida, é por quem eu vivo, é o motivo de todos os meus sorrisos e o que mais faz levantar quando eu não tô bem, quanto eu tô fraca, é o que me faz forte, é o meu combustível para viver, filho eu acho que pra mim é abaixo de Deus, é pra mim, talvez, é uma expressão do que é Deus pra mim, é o que hoje são os meus filhos, né? (LAURA, 2019. Informação verbal)

Ah, filho significa tudo, é uma alegria imensa, é poder tomar conta, ficar com a pessoinha, formar, educar, filho é tudo, sem João eu não seria nada, só tô fazendo tudo por ele, tudo por ele, então acho que ele é tudo para gente, tanto para mim e pro pai, porque o pai pensa da mesma forma, que ele é tudo [...]. (FERNANDA, 2019. Informação verbal)

[...] filho, para mim, é uma extensão de mim e da minha família e dos meus conceitos e assim é um amor, um sentimento que você é capaz de mover tudo, você é capaz de se transformar, você consegue enxergar que você tem forças, que você achava que não teria e isso eu percebi muito, mas, assim, o que é um filho para mim, [...] o filho pra mim é minha razão das minhas conquistas, meus filhos, hoje é minha razão de eu buscar, melhorar o mundo, melhorar como ser humano, melhorar o meio ambiente que eles vivem, então para mim é um direcionamento, meus filhos." (TALITA, 2019. Informação verbal)

É interessante notar que o conteúdo da entrevista de Talita, por exemplo, expressa as idealizações em relação ao filho - e ressignificações sobre si mesma -, já que ela fala sobre a expectativa de um filho que representa uma extensão dela e da sua família. Dessa forma, esse filho cumpriria com a continuidade do histórico da sua família e daquilo que é esperado socialmente e, consequentemente, pelos pais quando se projetam em seus filhos. Segue mais um trecho ilustrativo:

[...] você acha que seu filho vai se formar na faculdade, independente se for médico, engenheiro, se for advogado ou se for economista, né? Vai ter um curso de nível superior, vai te dar uns netos, vai constituir uma família, vai ser capaz de viajar, você vai trabalhar para conseguir pôr numa escola que você escolha e que seja uma escola boa para você e para ele [...]. (TALITA, 2019. Informação verbal) 
As mães entrevistadas relataram questões relacionadas à recepção de um filho que não cumpre com o padrão idealizado e confirmaram as dificuldades emocionais presentes no processo de ressignificação que, conforme Alves (2012), muitas vezes, apresentam-se também através de sintomas corporais, como é possível notar nos trechos destacados a seguir: "[..] veio para nós um misto de sentimentos, um misto de emoções, uma impotência de você não achar que você seja capaz de cuidar, de oferecer o melhor para essa criança [...].” (LAURA, 2019. Informação verbal).

Oliveira e Poletto (2015) apontam que, além do desgaste emocional, existem implicações físicas. Isso se mostrou evidente nas entrevistas realizadas com as mães, como é possível visualizar logo a seguir: “[...] então, tive problemas físicos reais, é eu tive, não consegui amamentar de forma alguma, eu tive sensações de estresse muito grande, eu tive taquicardia, eu tive falta de ar, choros compulsivos [...]." (TALITA, 2019. Informação verbal).

Oliveira e Poletto (2015) se referem à perda do filho desejado - idealizado - como uma ferida no narcisismo dos pais. Assim, é necessário abrir mão da fantasia para dar espaço a uma nova concepção do filho, a qual não atenderá às idealizações anteriores. Tal processo exige que novas expectativas sejam criadas, respeitando as características do ser que acaba de nascer. As mães entrevistadas refletem em suas falas essa ressignificação:

[...] João é desse jeito, então tem que aceitar do jeito que ele é e lutar pra, também, ele ser aceito [...]. (FERNANDA, 2019. Informação verbal)

[...] isso não é o fim do mundo, apenas uma janela nova, que precisa abrir, uma nova visão para enxergar o mundo de uma outra forma [...]. (TALITA, 2019. Informação verbal)

[...] parece que você morre para você renascer naquele momento [...]. (LAURA, 2019. Informação verbal)

Nesse processo, a família terá demandas para as quais não se preparou, bem como a exigência de adaptar os planos já esperados levando em consideração as dificuldades e 
as limitações da criança, tais como a criação e o estreitamento de vínculos, formação de autonomia, fortalecimento da autoestima, inclusão na sociedade etc. (OLIVEIRA; POLETTO,2015). Sobre tais demandas, uma das mães relata: “[...] ficamos uma semana assim, completamente atordoados, sem saber por que caminho seguir [...] é uma insegurança com relação às decisões que você vai precisar tomar, porque vão impactar na vida dessa criança [...]." (Fernanda, 2019. Informação verbal).

Segundo Kübler-Ross (1969), durante o luto é possível observar mecanismos de defesa ou de luta que auxiliam no enfrentamento desse processo. A autora aponta que não existe uma regra quanto à duração das fases do luto, pois podem alternar-se entre si. Entretanto, a única coisa que considera consistente e presente, na maioria dos casos e em todos os estágios, é a esperança. Dessa forma, a partir dos relatos das mães, nota-se que, através da experiência do luto e da ressignificação, é possível descobrir, na vivência com uma criança dentro do TEA, o que é de fato o autismo: "mais do que se poderia imaginar."

\section{Famílias x TEA}

Com o passar dos anos, a importância da família no desenvolvimento das crianças dentro do TEA foi percebida tanto por estudiosos como pela sociedade, tendo em vista o grande potencial que esta exerce na assistência de saúde mental, podendo promover mudanças e permitindo bons resultados de acolhimento e ressocialização (Borba et al., 2011). Para Santos e Pereira-Martins (2016), o apoio social é de suma importância para o desenvolvimento saudável da criança, pois um ambiente estável e seguro facilita o processo. Nesse sentido, é imprescindível entender que a família é um círculo social importante para todo ser humano, já que é nesse contexto que obtemos o primeiro contato com interações enquanto seres humanos pertencentes a uma organização social.

Nesse mesmo contexto, as famílias passam por várias situações que exigem ajustamento por parte dos seus membros. Esse grupo não é só formado por um conjunto de pessoas do mesmo sangue, mas, também, pelas relações e ligações comuns entre elas, o que permite maior resiliência ao passar por mudanças. Quanto mais significativos forem esses laços, maior será a probabilidade da família atravessar tais situações, estabelecer novos significados e um fortalecimento e, em contrapartida, caso a ligação não seja tão 
forte, a estrutura familiar desmorona (Borba et al., 2011). Foi possível perceber, nos relatos das mães entrevistadas, aspectos que ressaltam a importância do apoio familiar, como se verifica na fala de Fernanda: "[...] eu e meu marido temos que reunir forças e fazer tudo que podemos, para fazer com que João tenha o melhor e fazer com que João consiga se desenvolver, que é o que mais a gente quer [...]." (FERNANDA, 2019. Informação verbal).

Foi possível observar, também, a participação das mães no desenvolvimento do filho, como alega Talita, a qual abriu mão da vida profissional para se dedicar aos cuidados direcionados ao filho: “[...] então eu não pensei duas vezes, sabe, eu abri mão de tudo que almejava para mim, na minha vida profissional [...]”. (TALITA, 2019. Informação verbal)

Para Santos e Pereira-Martins (2016), quando existe relação entre as estratégias encontradas e a satisfação da vida familiar, há a promoção de uma boa qualidade nas relações, seja em prol de si ou do outro. A possibilidade das mães darem maior atenção à vida familiar é mais satisfatória para as mesmas, pois, assim, cria-se uma maior possibilidade de vínculo afetivo e satisfação própria, como percebemos na seguinte fala:

[...] porque eu sei que eu ia me culpar, na verdade é isso, não é nem pela criança era mais por mim, porque eu sei que ia me culpar se eu não desse meu melhor, e meu filho não conseguisse alcançar o que ele poderia alcançar pela minha ausência ou pelo meu egoísmo de preferir me priorizar com relação a ele, então assim, isso [...]. (TALITA)

\section{Manobras}

Dado o momento de ressignificação do que é "filho", as famílias se deparam com estratégias de enfrentamento que percorrem caminhos para, assim, passar pelas fases do luto do filho "ideal", e podem aliviar sobrecargas de demandas. As três mães relataram, como principal estratégia de enfrentamento, a busca pelo estudo e por conhecimento: 
[...] eu busquei primeiro criar um projeto e me engajar com um grupo de pais e discutir e me relacionar com outras famílias, essa foi a principal estratégia [...]. (LAURA, 2019. Informação verbal)

[...] então o conforto que tive foi ler artigos, na família e na religião [...]. (TALITA, 2019. Informação verbal)

[...] eu acho que se preparar, estudar sobre o autismo, é ver quais seriam os caminhos que seriam melhores para ele, para o desenvolvimento dele [...]. (FERNANDA, 2019. Informação verbal)

A estratégia caracterizada como ação direta, conforme afirmam Schmidt, Dell'Aglio e Bosa (2007), está diretamente ligada à busca por conhecimentos que auxiliem no manejo das situações que envolvem a criança dentro do TEA; a importância dessa estratégia fica clara pois permite à família encontrar soluções objetivas e práticas para as situações estressoras que se revelam. Porém, os autores ainda apontam que os familiares podem assumir, também, uma estratégia de busca pelo apoio social e/ou religioso, na tentativa de reduzir os efeitos da situação estressora. Sobre isso, as mães relatam o seguinte:

[...] conhecer outras mães que passam (pela mesma situação), pelo menos para a gente poder trocar experiências [...]. (FERNANDA, 2019. Informação verbal)

[...] porque quando você abraça e recebe o abraço de pessoas que estão na mesma condição que você, você percebe que não está sozinho [...] (LAURA, 2019. Informação verbal)

Então eu busquei basicamente me fortalecer com minha família e busquei a religião também, fiz minhas orações. Busquei quem me orientasse, para ver como deveria lidar com essa situação. (TALITA, 2019. Informação verbal)

Uma rede de apoio segura promove a proteção necessária para o desenvolvimento familiar, bem como auxilia na superação de crises. Seibel e colaboradores (2017) evidenciam a interação entre as famílias de forma positiva, afirmando que, quanto maior a qualidade da rede de apoio, melhor será o funcionamento familiar. A religião e a espiritualidade são estratégias de enfrentamento particularmente efetivas, já que são associadas à resiliência e à resistência ao estresse, à proteção da 
saúde e à prevenção de doenças, como, por exemplo, a depressão e os transtornos de ansiedade. Além de promover conforto na conexão com o transcendental e a transformação da situação estressora em algo benéfico, esse tipo de estratégia está relacionada também a uma busca por sentido de vida e ao autoperdão (PANZINI; BANDEIRA, 2007).

\section{Considerações finais}

A partir dos relatos mencionados sobre o modo como as famílias enfrentam a questão do diagnóstico do TEA, compreende-se que os resultados desta pesquisa podem contribuir para familiares, profissionais de saúde, de escolas e estudantes, como também para sociedade. Foi possível notar, de modo geral, que os significados atribuídos ao filho apontam para o amor, carinho, sacrifício e redenção. Acerca da investigação sobre como a família enfrenta a perda do filho "ideal”, as três mães relataram seus impasses e os caminhos para a ressignificação das representações do filho, de modo que foram compreendendo e se situando no processo de aceitação.

Com relação à identificação das estratégias de enfrentamento encontradas pela família no desenvolvimento dos seus filhos e as suas repercussões, as mães buscaram aprender o que significava o TEA e o que poderiam fazer para ajudar no desenvolvimento das crianças. Elas buscaram o apoio da família, o apoio da religião e do conhecimento para seus filhos. O acesso à informação mostrou-se como um importante aliado no processo de enfrentamento das dificuldades das famílias ao receberem o diagnóstico de TEA. Além disso, essa busca pelo saber diminuiu, para essas mães, as inseguranças e os medos, facilitando o encontro de práticas que ajudassem o filho em seu desenvolvimento e, consequentemente, aumentando a sensação de satisfação da família. Entretanto, compreendemos que o excesso dessa busca pelo conhecimento também pode ser prejudicial, principalmente para as crianças, quando o saber científico/profissional regula, prioritariamente, a relação entre a família e o filho.

Considera-se, a partir dos resultados de pesquisa, que é imprescindível a realização de estudos acerca da família de crianças com TEA, visando promover ações que permitam a reorganização das estratégias frente ao estresse familiar ocasionado pelo luto do filho 
“ideal”, assim como de uma família “ideal”. É relevante buscar melhorias e conhecimentos de serviços que apoiem e problematizem as questões do TEA, permitindo a ascensão de ambientes, sejam eles no contexto familiar e/ou social da criança e de toda estrutura familiar, os quais permitam a autonomia e os avanços nas relações e no desenvolvimento da criança diagnosticada.

Além disso, é importante lembrar que esta pesquisa foi realizada com famílias de classe média alta, as quais possuem acesso a conhecimentos e a profissionais especializados na área, facilitando, assim, uma ação direta baseada nas produções científicas. E ainda, tais famílias estão inseridas em espaços que promovem debates reflexivos e críticos sobre as questões referentes ao tema. Portanto, mesmo que este estudo não reflita a situação geral de famílias com crianças dentro do TEA, pode abrir espaço para que pesquisas futuras sejam realizadas com famílias de camadas populares.

\section{Referências}

ALVES, Elaine Gomes dos Reis. A morte do filho idealizado. O Mundo da saúde, São Paulo, v. 36, n. 1, p. 90-97, 2012.

AMERICAN PSYCHIATRIC ASSOCIATION. DSM-5: manual diagnóstico e estatístico de transtornos mentais. Porto Alegre: Artmed, 2014.

BATISTA, Cristina Abranches Mota. Autismo, política e instituição. Trivium, Rio de Janeiro, v. 5, n. 1, p. 46-63, 2013.

BEGOSSI, Janaina. O luto do filho perfeito: um estudo psicológico sobre os sentimentos vivenciados por mães com filhos portadores de paralisia cerebral. 2003. 127 f. Dissertação (Mestrado em Psicologia) - Universidade Católica Dom Bosco, Campo Grande, 2003.

BORBA Letícia de Oliveira; PAES, Marcio Roberto; GUIMARÃES, Andréa Noeremberg; LABRONICI, Liliana Maria; MAFTUM, Mariluci Alves. A família e o portador de transtorno mental: dinâmica e sua relação familiar. Revista da Escola de Enfermagem da USP, São Paulo, v. 45, n. 2, p. 442-449, abr. 2011.

BOSA, Cleonice Alves. Autismo: intervenções psicoeducacionais. Revista Brasileira de Psiquiatria, São Paulo, v. 28, p. S47-S53, maio 2006. Suplemento 1.

CAREGNATO, Rita Catalina Aquino; MUTTI, Regina. Pesquisa qualitativa: análise de 
discurso versus análise de conteúdo. Texto e Contexto Enfermagem, Florianópolis, v. 4, n. 15, p.679-684, out. 2016.

COSTA, Daniela Ferreira Cristina da. Intervenção precoce no transtorno do espectro do autismo. 2014. 105 f. Dissertação (Mestrado em Ciências da Educação) - Escola Superior de Educação João de Deus, Lisboa, 2014.

CRESWELL, John W. Métodos quantitativos. In: CRESWELL, John W. Método de pesquisa: métodos qualitativo, quantitativo e misto. 2. ed. Porto Alegre: Artmed, 2007.

FAVERO-NUNES, Maria Angela; SANTOS, Manoel Antônio dos. Itinerário terapêutico percorrido por mães de crianças com transtorno autístico. Psicologia - Reflexão e Crítica, Porto Alegre, v. 23, n. 2, p. 208-221, 2010.

GADIA, Carlos A.; TUCHMAN, Roberto; ROTTA, Newra T. Autismo e doenças invasivas de desenvolvimento. Jornal de Pediatria (Rio J.), Porto Alegre, v. 80, n. 2, supl. p. 83-94, 2004 .

GERHARDT, Tatiana Engel. RAMOS, Ieda Cristina Alves; RIQUINHO, Deise Lisboa; SANTOS, Daniel Labernarde dos. Unidade 4: estrutura do projeto de pesquisa. In: GERHARDT, Tatiana Engel; SILVEIRA, Denise Tolfo (org.). Métodos de pesquisa. Porto Alegre: Ufrgs, 2009. p. 65-87.

GIL, Antonio Carlos. Métodos e técnicas de pesquisa social. 6. ed. São Paulo: Atlas, 2008.

GOMES, Romeu. A análise de dados em pesquisa qualitativa. In: MINAYO, Maria Cecília de Souza (org.). Pesquisa social: teoria, método e criatividade. 21. ed. Petrópolis: Editora Vozes, 2002. p. 67-80.

GONÇALVES, Paulo Cesar; BITTAR, Cléria Maria Lobo. Estratégias de enfrentamento no luto. Mudanças - Psicologia da saúde, São Paulo, v. 24, n. 1, p. 39-44, jan./jul. 2016.

Disponível em: https://pesquisa.bvsalud.org/portal/resource/pt/biblio-835048. Acesso em: 13 jun. 2019.

GONCALVES, Amanda Pilosio et al. Transtornos do espectro do autismo e psicanálise: revisitando a literatura. Tempo psicanalítico, Rio de Janeiro, v. 49, n. 2, p. 152-181, 2017.

KLIN, Ami. Autismo e síndrome de Asperger: uma visão geral. Revista Brasileira de Psiquiatria, São Paulo, v. 28, p. s3-s11, 2006. Suplemento 1.

KÜBLER-ROSS, Elisabeth. Sobre a morte e o morrer: o que os doentes terminais têm para ensinar a médicos, enfermeiras, religiosos e aos seus próprios parentes. São Paulo:

Editora Martins Fontes, 1969. 
LAMPREIA, Carolina. A perspectiva desenvolvimentista para a intervenção precoce no autismo. Estudos de Psicologia, Campinas, v. 24, n. 1, p. 105-114, 2007.

LEVIN, Esteban. A infância do outro corpo. In: LEVIN, Esteban. Clínica e educação com as crianças do outro espelho. Petrópolis: Vozes, 2005.

MACEDO, Carina Rugai Moreira de. A função continente e o uso da contratransferência como instrumentos na psicoterapia de grupo com pacientes com severas perturbações no desenvolvimento do psiquismo. Vínculo, São Paulo, v. 7, n. 2, p. 16-23, 2010.

MAIA, Fernanda Alves; ALMEIDA, Maria Tereza Carvalho; OLIVEIRA, Liliane Marta Mendes de; OLIVEIRA, Stéffany Lara Nunes; SAEGER, Vanessa Souza de Araújo; OLIVEIRA, Victória Spínola Duarte de; SILVEIRA, Marise Fagundes. Importância do acolhimento de pais que tiveram diagnóstico do transtorno do espectro do autismo de um filho. Cadernos Saúde Coletiva, [s.l.], v. 24, n. 2, p.228-234, jun. 2016. Disponível em:

http://dx.doi.org/10.1590/1414- 462×201600020282. Acesso em: 20 out. 2019.

MANNONI, Maud. A criança retardada e a mãe. São Paulo: Livraria Martins Fontes Editora Ltda, 1985. $164 \mathrm{p}$.

MARFINATI, Anahi Canguçu; ABRÃO, Jorge Luís Ferreira. Um percurso pela psiquiatria infantil: dos antecedentes históricos à origem do conceito de autismo. Estilos da clínica, São Paulo, v. 19, n. 2, p. 244-262, 2014.

MONTEIRO, Andréa Freire; PIMENTA, Ricardo de Almeida; PEREIRA, Suzana Matheus; ROESLER, Helio. Considerações sobre critérios diagnósticos de transtorno do espectro autista, e suas implicações no campo científico. Do Corpo: Ciências e Artes, Caxias do Sul, v. 7, n. 1, p.1-11, jan. 2017.

MOYSÉS, Maria Aparecida Affonso; COLLARES, Cecília Azevedo Lima. Inteligência Abstraída, Crianças Silenciadas: as Avaliações de Inteligência. Psicologia Usp, [s.I.], v. 8, n. 1, p.63-89, 1997.

OLIVEIRA, Isaura Gisele de; POLETTO, Michele. Vivências emocionais de mães e pais de filhos com deficiência. Revista SPAGESP, Ribeirão Preto, v. 16, n. 2, p. 102-119, 2015.

PANZINI, Raquel Gehrke; BANDEIRA, Denise Ruschel. Coping (enfrentamento) religioso/espiritual. Revista de psiquiatria clínica, São Paulo, v. 34, p. 126-135, 2007. Suplemento 1.

PAULA, Cristiane Silvestre; BELISASIO FILHO, José Ferreira; TEIXEIRA, Maria Cristina Triguero Veloz. Estudantes de psicologia concluem a graduação com uma boa formação em autismo? Psicologia - teoria e prática, São Paulo, v. 18, n. 1, p. 206-221, abr. 2016. 
PINTO, Rayssa Naftaly Muniz et al. Autismo infantil: impacto do diagnóstico e repercussões nas relações familiares. Revista Gaúcha de Enfermagem, Porto Alegre, v. 37, n. 3, 2016.

RAMOS, Laísa Wendland. A (des)construção da idealização de um filho. 2015. 28 f. TCC (Graduação em Psicologia) - Universidade Regional do Noroeste do Estado do Rio Grande do Sul, ljuí, 2015.

ROCHA, Fúlvio Holanda. Questões sobre a alteridade no autismo infantil. Estilos da clínica, São Paulo, v. 14, n. 27, p. 150-171, 2009.

SANTOS, Manoel Antonio dos; PEREIRA-MARTINS, Maria Laura de Paula Lopes. Estratégias de enfrentamento adotadas por pais de crianças com deficiência intelectual. Ciência \& Saúde Coletiva, [s.I.], v. 21, n. 10, p.3233-3244, out. 2016.

SCHMIDT, Carlo; DELL'AGLIO, Débora Dalbosco; BOSA, Cleonice Alves. Estratégias de coping de mães de portadores de autismo: lidando com dificuldades e com a emoção. Psicologia - Reflexão e Crítica, Porto Alegre, v. 20, n. 1, p. 124-131, 2007.

SEIBEL, Bruna Larissa et al. Rede de apoio social e funcionamento familiar: estudo longitudinal sobre famílias em vulnerabilidade social. Pensando famílias, Porto Alegre, v. 21, n.1, p.120-136, jul.2017.

SILVA, Micheline; MULICK, James A. Diagnosticando o transtorno autista: aspectos fundamentais e considerações práticas. Psicologia, ciência e profissão, Brasília, v. 29, n. 1, p. 116-131, 2009.

SOUSA, Sônia M. Gomes; PERES, Vannúzia Leal Andrade. Famílias de camadas populares: um lugar legítimo para a educação/formação dos filhos. $\mathbf{O}$ social em questão, Rio de Janeiro, v. 6, n. 7, p. 63-74, 2002.

VIÉGAS, Lygia de Sousa. Progressão Continuada e patologização da educação: um debate necessário. Psicologia Escolar e Educacional, [s.l.], v. 19, n. 1, p.153-161, abr. 2015.

VILLARES, Cátia; LAGE, Yeda. Melancolia materna: entre o filho idealizado e o filho da realidade. 2017. 22 f. TCC (Graduação em Psicologia) - Faculdade Ciências da Vida - Fcv, Sete Lagoas, 2017.

WILLIAMS, Chris; WRIGHT, Barry. Convivendo com autismo e síndrome de Asperger: estratégias práticas para pais e profissionais. São Paulo: M. Books do Brasil, 2008. 
Recebido em: 05/01/2020

Aprovado em: 12/01/2021

Universidade do Estado de Santa Catarina - UDESC

Centro de Ciências Humanas e da Educação - FAED

PerCursos

Volume 21 - Número 47 - Ano 2020 revistapercursos@gmail.com 